ISSN: 02162938

\title{
EFEKTIFITAS METODE REINFORCEMENT GUNA MENINGKATKAN MOTIVASI BELAJAR PADA SISWA KELAS X SMKS AL KAAFFAH KEPANJEN
}

\author{
Siti Mardiana Hindayati, S.Psi. \\ SMK AL KAAFFAH KEPANJEN-MALANG \\ sitimardianahindayati@gmail.com
}

\author{
Diana Mayasari \\ SMK Negeri 1 Pacitan \\ bunda.diana.mayasari@gmail.com
}

\begin{abstract}
Abstrak
Permasalahan mengenai motivasi belajar sangat sering muncul dikalangan siswa atau peserta didik. Jika siswa memiliki motivasi belajar rendah otomatis dia tidak bisa mengikuti proses pembelajaran dengan baik. Menerima materi dengan asal-asalan bahkan untuk menyelesaikan tugas juga pasti tidak maksimal. Sedangkan reinforcement memegang peranan yang cukup penting untuk meningkatkan motivasi belajar siswa. Sehingga tujuan dari penelitian ini adalah untuk mengetahui Efektifitas metode reinforcement guna meningkatkan motivasi belajar siswa kelas XI di SMKS AL KAAFFAH Kepanjen. Proses penelitian ini berlangsung dalam 2 siklus. Melalui layanan bimbingan konseling, pemberian tindakan reinforcement mulai diberikan pada siswa. Jenis penelitian ini adalah kuantitatif, dimana untuk pengambilan data peneliti menggunakan angket. Metode Analisa data pada penelitian ini adalah rating scale dan mengevaluasi hasil dari angket tersebut. Hasil penelitian menunjukkan bahwa pemberian reinforcement cukup efektif guna meningkatkan motivasi belajar pada siswa.
\end{abstract}

Kata Kunci: Masalah Belajar, Eklektif, Konseling

\begin{abstract}
Problems regarding learning motivation very often arise among students or students. If students have low learning motivation, automatically they cannot follow the learning process well. Accepting material carelessly even to complete assignments is definitely not optimal. Meanwhile, reinforcement plays an important role in increasing student motivation. So that the purpose of this study was to determine the effectiveness of the reinforcement method in order to increase the learning motivation of class XI students at AL KAAFFAH Kepanjen SMKS. This research process took place in 2 cycles. Through counseling guidance services, giving reinforcement measures began to be given to students. This type of research is quantitative, where the researcher uses a questionnaire to collect data. The data analysis method in this study is a rating scale and evaluates the results of the questionnaire. The results showed that reinforcement was effective enough to increase student motivation.
\end{abstract} Keywords: Learning Problems, Eclectic, Counseling 
Jurnal HELPER, Vol 36 No 2 (2018) Edisi 1

Bimbingan dan Konseling Universitas PGRI Adi Buana Surabaya

ISSN: 02162938

\section{LATAR BELAKANG}

Motivasi memiliki peranan penting dalam proses pembelajaran baik bagi guru maupun bagi siswa, karena motivasi ini berperan sebagai pendorong seseorang untuk mengikuti proses pembelajaran. Jika siswa memiliki motivasi belajar rendah otomatis dia tidak bisa mengikuti proses pembelajaran dengan baik. Menerima materi dengan asalasalan bahkan untuk menyelesaikan tugas juga pasti tidak maksimalSalah satu yang menjadi masalah dalam motivasi yakni bagaimana mendorong siswa agar di dalam dirinya tumbuh motivasi untuk belajar. Untuk mengatasi masalah tersebut seorang guru harus mengetahui dulu faktor apa saja yang menyebabkan rendahnya motivasi belajar siswa dalam belajar.

Menurut Sardiman, AM : 2000 Motivasi belajar merupakan faktor psikis yang bersifat non intelektual. Perannya yang khas adalah dalam hal penambah gairah, merasa senang dan semangat dalam belajar. Siswa yang memiliki motivasi yang kuat, akan memiliki banyak energi untuk melakukan kegiatan belajar.

Secara umum, dalam hubungannya dengan belajar, para ahli sepakat mengklasifikasikan motivasi ke dalam dua jenis menurut timbulnya, yaitu motivasi intrinsik dan motivasi ekstrinsik. Motivasi intrinsik adalah hal dan keadaan yang berasal dari dalam diri siswa sendiri yang dapat mendorongnya melakukan tindakan belajar. Sedangkan motivasi ekstrinsik adalah hal dan keadaan yang datang dari luar individu siswa yang mendorongnya untuk melakukan kegiatan belajar.

Untuk itu sebagai seorang guru harus mempunyai strategi yang tepat untuk membangkitkan motivasi belajar siswa agar prestasi belajarnya meningkat. Salah satu strategi yang bisa digunakan oleh guru untuk meningkatkan motivasi belajar siswa adalah dengan pemberian reinforcement atau penguatan melalui layanan bimbingan dan konseling.

Reinforcement ini salah satu hal yang wajib diterapkan dalam setiap proses pembelajaran karena reinforcement adalah bagian dari keterampilan dasar mengajar

Menurut Moh. Uzer Usman penguatan (reinforcement) adalah segala bentuk respon, apakah bersifat verbal ataupun nonverbal, yang merupakan bagian dari modifikasi tingkah laku guru terhadap tingkah laku siswa, yang bertujuan untuk memberikan informasi atau umpan balik bagi si penerima (siswa) atas perbuatannya sebagai suatu tindakan dorongan ataupun koreksi. Mudjiran (2011) menyatakan bahwa penguatan terhadap tingkah laku positif sangat efektif untuk merubah tingkah laku seseorang. Siswa akan terus berupaya untuk meningkatkan hasil belajar jika ia memperoleh motivasi dari luar yang berupa reinforcement positif. Rohani (2010:16).

Menurut teori yang disampaikan oleh Hasibuan (2012:58) mengungkapkan tujuan penguatan atau reinforcement adalah (1) meningkatkan perhatian siswa, (2) 
Jurnal HELPER, Vol 36 No 2 (2018) Edisi 1

Bimbingan dan Konseling Universitas PGRI Adi Buana Surabaya

ISSN: 02162938

melancarkan proses belajar,

membangkitkan dan mempertahankan motivasi, (4) mengontrol sikap yang mengganggu kearah tingkah laku belajar yang produktif, (5) mengembangkan dan mengatur diri sendiri dalam belajar, (6) mengarahkan kepada cara berpikir yang baik dan inisiatif pribadi.

Sedangkan menurut Mulyasa ada tiga tujuan pemberian penguatan yaitu meningkatkan perhatian siswa terhadap pembelajaran, (2) merangsang dan meningkatkan motivasi belajar, (3) meningkatkan kegiatan belajar dan membina perilaku laku yang produktif.

Dari latar belakang tersebut akhirnya penulis mengambil sebuah judul penelitian "Efektifitas Metode Reinforcement Guna Meningkatkan Motivasi Belajar Pada Siswa Kelas XI SMKS Al Kaaffah Kepanjen "

\section{Rumusan Masalah}

Berdasarkan penjabaran pada latar belakang masalah diatas, maka masalah dalam penelitian ini adalah "bagaimana efektifitas metode reinforcement guna meningkatkan motivasi belajar siswa kelas XI di SMKS AL KAAFFAH Kepanjen?”

\section{Tujuan Penelitian}

Penelitian ini bertujuan untuk mengetahui Efektifitas metode reinforcement guna meningkatkan motivasi belajar siswa kelas XI di SMKS AL KAAFFAH Kepanjen.

\section{METODE}

Sampel yang diambil dalam penelitian tindakan kelas ini adalah 5 orang siswa kelas XI SMK Al Kaaffah Kepanjen, yang belum memiliki motivasi belajar yang baik. Siswa masih memiliki keaktifan yang rendah dalam mengikuti pembelajaran. Di catatan nilai guru mapel, siswa memiliki 5 atau lebih nilai yang dibawah KKM, nama siswa tersebut sering muncul di laporan walas tiap bulan dengan catatan motivasi belajar kurang, siswa mendapat panggilan keruang BK lebih dari 2 kali dalam 2 minggu karena permasalahan motivasi belajar. Banyak siswa yang bergurau sendiri, melamun dan mengantuk serta tidak mengumpulkan tugas tepat waktu bahkan banyak juga yang tidak mengumpulkan tugas.

Tempat penelitian ini adalah di SMK Al Kaaffah Kepanjen, dimana pemberian tindakan Reinforcement dilakukan dengan menggunakan layanan konseling kelompok.

Penelitian ini menggunakan model penelitian tindakan dari Kemmis dan Taggart (dalam Sugiarti, 1997: 6), yaitu berbentuk spiral dari siklus yang satu ke siklus yang berikutnya. Setiap siklus meliputi planning (rencana), action (tindakan), observation (pengamatan), dan reflection (refleksi). Langkah pada siklus berikutnya adalah perencanaan yang sudah direvisi, tindakan, pengamatan, dan refleksi.

Pada pelaksanaan siklus I, peneliti melakukan layanan konseling kelompok yang akan dilakukan dengan memberikan reinforcement selama proses layanan berlangsung. Guru BK melakukan 
Jurnal HELPER, Vol 36 No 2 (2018) Edisi 1

Bimbingan dan Konseling Universitas PGRI Adi Buana Surabaya

ISSN: 02162938

pengamatan terhadap siswa selama proses layanan. Untuk mengetahui motivasi belajar dari siswa di awal, dapat dilihat dari hasil angket yang dibagikan. Untuk melihat peningkatan motivasi belajar siswa, akan diberikan angket lagi pada siklus ke 2. Setelah siklus I dilaksanakan, akan dilakukan refleksi untuk mengevaluasi kegiatan selama pelaksanaan siklus. Apabila hasil yang diharapkan belum tercapai maka dapat dilakukan tindakan yang berbeda dengan mengulang tahap-tahap yang ada di siklus 1 .

Pada penelitian ini terdapat data yang didapatkan dalam proses pengembangan, yaitu data kuantitatif. Data kuantitatif yang diperoleh dalam proses penelitian ini berupa skor hasil penilaian angket respon siswa dan lembar observasi keterlaksanaannya tindakan reinforcement. Angket respon siswa digunakan untuk mengukur kepraktisan produk yang dikembangkan. Penggunaan angket menganalisis tingkat keberhasilan atau persentase pemberian reinforcement terhadap peningkatan motivasi belajar siswa.

\section{HASIL}

Peneliti disini berperan sebagai konselor. Memberikan tindakan berupa reinforcement yang dilakukan dalam proses konseling kelompok yang diikuti oleh 5 orang siswa yang menjadi subyek penelitian. Dari data awal yang diperoleh dalam penelitian siklus 1 diperoleh data sebagai berikut:
Tabel 1

Hasil Observasi pemberian reinforcement yang diberikan pada siklus 1

\begin{tabular}{|c|c|c|}
\hline \multirow[b]{2}{*}{ Reinforcement yang diberikan } & \multicolumn{2}{|c|}{ Siklus 1} \\
\hline & Ada & $\begin{array}{c}\text { Tidak } \\
\text { Ada }\end{array}$ \\
\hline $\begin{array}{l}\text { 1. Penguatan Verbal } \\
\text { a. Baik } \\
\text { b. Bagus } \\
\text { c. Hebat sekali } \\
\text { d. Good } \\
\text { e. Oke }\end{array}$ & $\begin{array}{l}\mathrm{V} \\
\mathrm{V}\end{array}$ & $\begin{array}{l}\text { V } \\
\text { V }\end{array}$ \\
\hline $\begin{array}{l}\text { 2. Penguatan berupa } \\
\text { mimik dan Gerakan } \\
\text { badan } \\
\text { a. Senyum } \\
\text { b. Ceria } \\
\text { c. Acungan jempol }\end{array}$ & $\begin{array}{l}\text { V } \\
\text { V } \\
\text { V }\end{array}$ & \\
\hline $\begin{array}{l}\text { 3. Penguatan berupa } \\
\text { symbol atau benda } \\
\text { a. Makanan } \\
\text { b. Hadiah }\end{array}$ & V & V \\
\hline $\begin{array}{l}\text { 4. Penguatan berupa } \\
\text { kegiatan yang } \\
\text { menyenangkan } \\
\text { a. Cerita }\end{array}$ & & V \\
\hline
\end{tabular}

Tabel 2

Hasil Angket Motivasi Siklus 1

\begin{tabular}{|c|l|c|c|}
\hline No & Nama & $\begin{array}{c}\text { Skor siklus } \\
1\end{array}$ & Siklus 1 \\
\hline 1 & Devana & $24 \%$ & Cukup \\
\hline 2 & Sofi & $25 \%$ & Cukup \\
\hline 3 & Irwanda & $18 \%$ & Kurang \\
\hline 4 & Nisa & $25 \%$ & Cukup \\
\hline 5 & Rina & $18,2 \%$ & Kurang \\
\hline
\end{tabular}


Jurnal HELPER, Vol 36 No 2 (2018) Edisi 1

Bimbingan dan Konseling Universitas PGRI Adi Buana Surabaya

ISSN: 02162938

Dari hasil pemberian reinforcement siklus 1,

Tabel 4

masih ada siswa yang memiliki motivasi

Hasil Angket Motivasi Siklus 2

belajar yang kurang. Jadi peneliti memberikan tambahan tindakan melalui siklus 2. Dimana pada siklus 2 ini reinforcement dilakukan dengan lebih intens, berulang-ulang dan bervariasi. Dari pelaksanaan pemberian tindakan di siklus 2 diperoleh hasil sebagai berikut:

Tabel 3

Hasil Observasi Pemberian

\section{Reinforcement Yang Diberikan Pada} Siklus 2

\begin{tabular}{|c|c|c|}
\hline \multirow{2}{*}{$\begin{array}{l}\text { Reinforcement yang } \\
\text { diberikan }\end{array}$} & \multicolumn{2}{|c|}{ Siklus 1} \\
\hline & Ada & $\begin{array}{c}\text { Tidak } \\
\text { Ada }\end{array}$ \\
\hline 1. Penguatan Verbal & & \\
\hline a. Baik & V & \\
\hline b. Bagus & V & \\
\hline c. Hebat sekali & $\mathrm{V}$ & \\
\hline d. Good & $\mathrm{V}$ & \\
\hline e. Oke & $\mathrm{V}$ & \\
\hline 2. Penguatan berupa & & \\
\hline $\begin{array}{l}\text { Gerakan badan } \\
\text { a. Senyum }\end{array}$ & V & \\
\hline b. Ceria & $\mathrm{V}$ & \\
\hline c. Acungan jempol & $\mathrm{V}$ & \\
\hline $\begin{array}{l}\text { 3. Penguatan berupa } \\
\text { symbol atau } \\
\text { benda }\end{array}$ & & \\
\hline a. Makanan & V & \\
\hline b. Hadiah & V & \\
\hline $\begin{array}{l}\text { 4. Penguatan berupa } \\
\text { kegiatan yang } \\
\text { menyenangkan }\end{array}$ & & \\
\hline a. Cerita & V & \\
\hline
\end{tabular}

\begin{tabular}{|c|l|l|l|}
\hline No & \multicolumn{1}{|c|}{ Nama } & $\begin{array}{c}\text { Skor } \\
\text { Siklus 2 }\end{array}$ & Siklus 2 \\
\hline 1 & Devana & $24,6 \%$ & Cukup \\
\hline 2 & Sofi & $26,8 \%$ & Cukup \\
\hline 3 & Irwanda & $24 \%$ & Cukup \\
\hline 4 & Nisa & $28,6 \%$ & Cukup \\
\hline 5 & Rina & $24,2 \%$ & Cukup \\
\hline
\end{tabular}

Dari data pada siklus 2 diatas, sudah menunjukkan ada peningkatan motivasi belajar siswa. Dari hasil data tersebut, peneliti merasa bahwa penelitian ini cukup sampai disini dan tidak perlu dilanjutkan lagi ke siklus berikutnya

\section{PEMBAHASAN}

Dari proses pelaksanaan siklus 1 dan siklus 2 peneliti melakukan analisis data dengan membandingkan data hasil siklus 1 dan siklus

2. Berikut perbandingan data yang dimaksud:

Tabel 5

\begin{tabular}{|c|l|c|c|c|c|}
\hline No & Nama & $\begin{array}{c}\text { Skor } \\
\text { Siklus } \\
1\end{array}$ & $\begin{array}{c}\text { Siklus } \\
1\end{array}$ & $\begin{array}{c}\text { Skor } \\
\text { siklus } \\
2\end{array}$ & $\begin{array}{c}\text { Siklus } \\
2\end{array}$ \\
\hline 1 & Devana & $24 \%$ & Cukup & $24,6 \%$ & Cukup \\
\hline 2 & Sofi & $25 \%$ & Cukup & $26,8 \%$ & Cukup \\
\hline 3 & Irwanda & $18 \%$ & Kurang & $24 \%$ & Cukup \\
\hline 4 & Nisa & $25 \%$ & Cukup & $28,6 \%$ & Cukup \\
\hline 5 & Rina & $18,2 \%$ & Kurang & $24,2 \%$ & Cukup \\
\hline
\end{tabular}

Dari hasil Analisa data diatas tentang efektifitas reinforcement guna meningkatkan motivasi belajar siswa pada siklus 1 dan siklus 2 setelah dilakukan tindakan dan perbandingan diantara 2 siklus tersebut mengalami peningkatan.Tentunya pemberian tindakan masuh bisa dilakukan secara berkala kepada siswa yang bersangkutan. Karena hasil yang 
Jurnal HELPER, Vol 36 No 2 (2018) Edisi 1

Bimbingan dan Konseling Universitas PGRI Adi Buana Surabaya

ISSN: 02162938

didapat masih pada taraf cukup, jadi tidak menutup kemungkinan bisa turun kembali.

\section{KESIMPULAN DAN SARAN}

Dari hasil pemaparan penelitian bimbingan konseling di atas, maka penulis dapat menyimpulkan bahwa pemberian reinforcement cukup efektif untuk meningkatkan motivasi belajar pada siswa. Hal ini tentunya dengan catatan bahwa tindakan yang diberikan berupa reinforcement, harus dilakukan berulang kali dan sesering mungkin. Disamping itu wujud respon pemberian reinforcement juga harus bervariasi dan disesuaikan dengan tindakan positif yang muncul dari siswa tersebut.

Penelitian ini bisa dikatakan masih jauh dari sempurna, akan tetapi proses perbaikan harus terus berjalan. Jadi diharapkan untuk semua komponen disekolah, hendaknya sering memberikan reinforcement atau penguatan pada siswa agar mereka merasa senang dan bersemangat. Sehingga berimbas pada kenaikan motivasi belahar siswa. Jika diketahui ada kelemahan pada anggota komponen sekolah, maka dapat diupayakan tindak lanjut agar yang bersangkutan bisa memperbaiki keterampilannya tersebut

\section{DAFTAR RUJUKAN}

A.M Sardiman (2011) Jurnal Penelitian Interaksi dan Motivasi Belajar Mengajar, Jakarta: Rajawali Press

Ardhana ,Wayan, Pokok-pokok ilmu jiwa bumi, (Surabaya : Usaha Nosional Ari Kunto1985)
Buchari Alma, Guru Professional: Menguasai Metode dan Terampil Mengajar, (Bandung: Alfabeta, 2010)

Dimyati dan Mujiono, Belajar dan Pembelajaran, (Jakarta: PT Asdi Mahastya, 2002).

Mudjiran (2011), Jurnal Penelitian Pengembangan Model Penugasan Terstruktur Kepada Siswa, Padang: Sukabina Press

Purwanto,M. Ngalim., (2011). Ilmu Pendidikan Teoritis dan Praktis. Rodakarya

Rohani (2010:16), Skripsi Pengaruh Pemberian Reinforcement Terhadap Motivasi Dan Hasil Belajar Siswa Kelas III Mapel Pkn SDN Se Gugus Nudi Kawruh Kec. Karanglewas Banyumas

Sarono, 2014, Buku Panduan Bimbingan dan Konseling di Sekolah, (Jakarta : PT. Binatama Cipta Pratama)

Shoimin, Aris., (2014). 68 Model Pembelajaran Inovatif dalam Kurikulum 2013. Yogyakarta: Ar-Ruzz Media

Usman (2013:80), Jurnal ilmiah Potensia,2019,Vol.4(1),13-17, Hubungan Reinforcement Terhadap Disiplin Anak Usia Dini di PAUD Pembina 1 Kota Bengkulu 